\title{
Chapter 11 \\ The Effect of Radiation on the Immune System in Pigs Affected by the Fukushima Daiichi Nuclear Power Plant Accident
}

\author{
Motoko Morimoto, Ayaka Kato, Jin Kobayashi, Kei Okuda, \\ Yoshikazu Kuwahara, Yasushi Kino, Yasuyuki Abe, Tsutomu Sekine, \\ Tomokazu Fukuda, Emiko Isogai, and Manabu Fukumoto
}

\begin{abstract}
It is extremely important to understand the mechanisms underlying the effect of radiation on animals including humans. Radiation potentially induces alterations of the immune system, which may cause serious diseases. The Fukushima Daiichi Nuclear Power Plant (FNPP) accident occurred in 2011, in which radioactive contaminants were released over a wide area. After farmers evacuated from the
\end{abstract}

M. Morimoto $(\bowtie) \cdot$ A. Kato $\cdot$ J. Kobayashi

School of Food, Agricultural, and Environmental Sciences, Miyagi University,

Sendai, Japan

e-mail: morimoto@myu.ac.jp

K. Okuda

Institute of Environmental Radioactivity, Fukushima University, Fukushima, Japan

Y. Kuwahara

Department of Pathology, Institute of Development, Aging and Cancer, Tohoku University, Sendai, Japan

Y. Kino

Department of Chemistry, Tohoku University, Sendai, Japan

Y. Abe

Faculty of Life and Environmental Sciences, Prefectural University of Hiroshima,

Hiroshima, Japan

T. Sekine

Institute for Excellence in Higher Education, Tohoku University, Sendai, Japan

T. Fukuda

Graduate School of Science and Engineering, Iwate University, Morioka, Japan

E. Isogai

Graduate School of Agricultural Sciences, Tohoku University, Sendai, Japan

M. Fukumoto

Department of Pathology, Institute of Development, Aging and Cancer, Tohoku University,

Sendai, Japan

School of Medicine, Tokyo Medical University, Tokyo, Japan 
ex-evacuation zone set within $20-\mathrm{km}$ radius from FNPP, pigs were left behind and unleashed in the zone (abandoned pigs). Their small intestine was considered to have been affected by the dietary intake of radioactive contaminants. The present study thus aimed to clarify the effect of radiation by investigating whether there is any alteration in the expression of genes encoding immune-related molecules and in morphology of the intestine of abandoned pigs. Microarray analysis revealed changes of the expression of various genes involved in inflammation and oxidative stress including IFN- $\gamma$, which is an important inflammatory cytokine, was highly elevated in abandoned pigs, and its expression level was correlated with radioactive cesium concentration in skeletal muscle. On the other hand, there were no morphological changes in the intestine. At the sampling stage of this study, only 1 year passed since the FNPP accident occurred, it would be premature to conclude that the identified alteration of gene expression was caused only by artificial radionuclides attributed to the FNPP accident. We need to continue monitoring the effect of long-term radiation exposure in living organisms in the ex-evacuation zone.

Keywords Small intestine $\cdot$ Immune responses · Gene expression · Plasma biochemistry $\cdot$ Swine

\subsection{Introduction}

The immune system is essential not only for host defense against pathogens but also for regulation of physiological functions. The immune cells and nonimmune cells cooperate to maintain homeostasis in the body. Their interaction is regulated by a range of biologically active substances called cytokines. A large number of cytokines have been found to play key roles in regulating immune responses and inflammation. The immune system consists of innate immunity, which mediates the initial reaction by neutrophils, macrophages and innate lymphocytes (ILCs), and adaptive immunity, which develops more slowly but produces a specific reaction against antigens by lymphocytes [1]. The lymphocytes, T and B lymphocytes, are the most important immune cells for the development of appropriate and effective reactions in various situations. Inappropriate immune responses, including cytokine imbalances, contribute to the development of persistent diseases [2]. Specifically, insufficient responses result in the establishment of infection, while excessive activation of the immune system may cause chronic inflammation, which is central to the pathogenesis of various diseases [3].

A large number of studies on the effect of radiation on the immune system have been performed in animal models. As mentioned above, disorders of the immune system are closely associated with several diseases, including cancer, neurodegeneration and inflammatory diseases. Therefore, it is important to understand the effect of radiation on the immune system. UNSCEAR 2006 Report summarized the details of the effect of radiation on the immune system as described in the literature [4]. Although no definitive conclusions have yet been drawn, it was suggested that 
radiation induces a shift toward an inflammatory profile that could increase the risk of diseases. Radiation-induced oxidative stress affects biomolecules in immune cells, which probably leads to abnormal T-cell differentiation and functions, promoting or controlling acute and chronic diseases. In other words, the interaction of radiation with the water molecules in living cells induces the production of free radicals. In terms of the consequences of this, it is well known that reactive oxygen species (ROS) activate nuclear factor kappa $\mathrm{B}(\mathrm{NF}-\mathrm{\kappa B})$ which regulates the expression of a large number of target genes involved in immune and inflammatory responses [5]. Chronic inflammation not only promotes carcinogenesis, malignant transformation, tumor growth, invasion and metastatic spread, but also regulates the immune system, which limits tumor growth [6]. At an inflammatory site, several immune cells produce inflammatory cytokines. The function of cytokines is to induce the proliferation, survival and growth of cells and modify their differentiation status. Thus, the cytokine profile may be a useful marker of the alteration of immune responses. Hayashi et al. found that TNF- $\alpha$, IFN- $\beta$ and IL- 6 increase in atomic bomb survivors (Hibakusha) [7]. Moreover, Matsuoka et al. found increased IL-6 after radiotherapy, which is associated with radioresistance [8]. Furthermore, Lugade et al. learned that IFN- $\gamma$ is upregulated following radiation in a melanoma model [9]. Recently, it has been suggested that this elevation of inflammatory cytokines makes an important contribution to radioresistance or radiosensitivity, as well as inducing or suppressing radiation-mediated immune responses [10]. However, most of the obtained data were collected from culture cells, and sufficient data from the field and in vivo are not available.

After the Great East Japan Earthquake on March 11, 2011, a huge amount of radioactive cesium (Cs) was released following the Fukushima Daiichi Nuclear Power Plant (FNPP) accident. After farmers evacuated from the ex-evacuation zone set within a $20-\mathrm{km}$ radius from FNPP, pigs were left behind and unleashed in the zone (abandoned pigs). We have constructed "the Group for Comprehensive Dose Evaluation in Animals from the Area Affected by the FNPP Accident" and have been continuing to monitor the effect of long-term radiation exposure among organisms living in the ex-evacuation zone. The immune system and physiological functions of pigs are very similar to those of humans [11-13]. Therefore, knowledge about the immunological responses of abandoned pigs to radioactive contamination can be useful to understand the effect of radiation on humans. Here, we report our data of abandoned pigs and discuss the consequence of the FNPP accident.

\subsection{Methods}

\subsubsection{Animals}

We collected peripheral blood from 53 euthanized pigs and obtained the intestinal and the skeletal muscle samples from 13 of them between January 18 and February 16, 2012, $5 \mathrm{~km}$ southwest of FNPP. The animals were sacrificed in 
accordance with the Regulations for Animal Experiments and Related Activities, Tohoku University, by veterinary doctors belonging to the Livestock Hygiene Service Center of Fukushima Prefecture [14]. Estimates of the amounts of ${ }^{134} \mathrm{Cs}$ and ${ }^{137} \mathrm{Cs}$ deposited on the ground have been reported [15]. Control intestine samples were obtained from three healthy pigs present in an uncontaminated pigsty in Miyagi Prefecture in 2012. Each experimental protocol was approved by the Institutional Ethics Commissions for Animal Research at Tohoku University and Miyagi University.

\subsubsection{Measurement of Radioactivity}

Radioactivity in the muscle samples was determined by $\gamma$-ray spectrometry using high-purity germanium (HPGe) detectors (Ortec Co., Oak Ridge, TN, USA), as described in our previous report [14]. Gamma-rays from ${ }^{134} \mathrm{Cs}$ and ${ }^{137} \mathrm{Cs}$ were observed and radioactivity ratios of ${ }^{134} \mathrm{Cs}$ to ${ }^{137} \mathrm{Cs}$ (decay corrected to March 15 , 2011) were 0.9-1.0, which corresponded to those of other samples polluted by the FNPP accident.

\subsubsection{Histological Analysis}

Small pieces of the small intestine were slit longitudinally, laid flat with the mucosal surface facing down and rolled around a wooden stick (Swiss roll). Paraffin blocks were prepared for pathomorphological examination using hematoxylin and eosin (HE) staining.

\subsubsection{Gene Expression Analysis}

Total RNA was extracted from the small intestine collected in 2012 using TRIzol reagent (Life Technologies, Inc., Frederic, MD, USA), in accordance with the manufacturer's instruction. RNA concentration was measured on a NanoDrop spectrophotometer (Thermo Scientific, Wilmington, DE, USA) and cDNA was synthesized with random primers and SuperScript II (Life Technologies, Inc.). cDNA samples were analyzed using a microarray (three pigs of control vs three abandoned pigs in the ex-evacuation zone) (V1: $4 \times 44 \mathrm{~K}$; Agilent Technologies, Palo Alto, CA, USA), and IFN- $\gamma$ gene expression was assessed by real-time PCR. Primer sequences were designed using Primer-BLAST with sequences obtained from GenBank [16]. 
Real-time PCR was performed using Brilliant SYBR Green QPCR Master Mix III (Stratagene, La Jolla, CA, USA) with an MX3000P system (Stratagene, La Jolla, CA, USA). Amplification conditions were as follows: $95^{\circ} \mathrm{C}$ for $3 \mathrm{~min}, 40-50$ cycles at $95^{\circ} \mathrm{C}$ for $5 \mathrm{~s}$ and $60{ }^{\circ} \mathrm{C}$ for $20 \mathrm{~s}$. Fluorescence signals measured during the amplification were analyzed. Ribosomal RNA primers were used as an internal control and all data were normalized to constitutive rRNA values. Quantitative differences between the groups were calculated in accordance with the manufacturer's instructions as expression ratio (Applied Biosystems, Foster City, CA, USA).

\subsubsection{Biochemical Testing}

Heparinized peripheral blood was collected from the jugular vein and immediately centrifuged to separate plasma and blood cells. Plasma samples were preserved at $-80{ }^{\circ} \mathrm{C}$ until use. Biochemical testing was performed with the Fuji Dri-Chem system (NX500; Fuji Film, Tokyo, Japan) to measure glutamic oxaloacetic transaminase (GOT), blood urea nitrogen (BUN) and total cholesterol (TCHO).

\subsubsection{Statistical Analysis}

All data are presented as mean \pm standard error (SE) for each treatment group. Differences in mRNA expression among the groups were determined using the $t$-test (Prism; GraphPad Software Inc., La Jolla, CA, USA). Differences were considered statistically significant at a $p$-value of $<0.05$.

\subsection{Results}

\subsubsection{Living Conditions of Pigs in the Ex-Evacuation Zone}

When our team started to investigate the effect of radiation on animals around and in the ex-evacuation zone, most of the abandoned pigs were unleashed. They were eating, sleeping and walking around outside the barn without restrictions, although they may not have had sufficient access to concentrated feed. However, the pigs looked healthy and clean, and no emaciation was observed (Fig. 11.1a), although some of them were infected by Trichuris suis (Fig. 11.1b), a typical whipworm in swine. Nonetheless, $T$. suis does not cause serious disease in adult pigs unless the host has an extremely high worm load. 

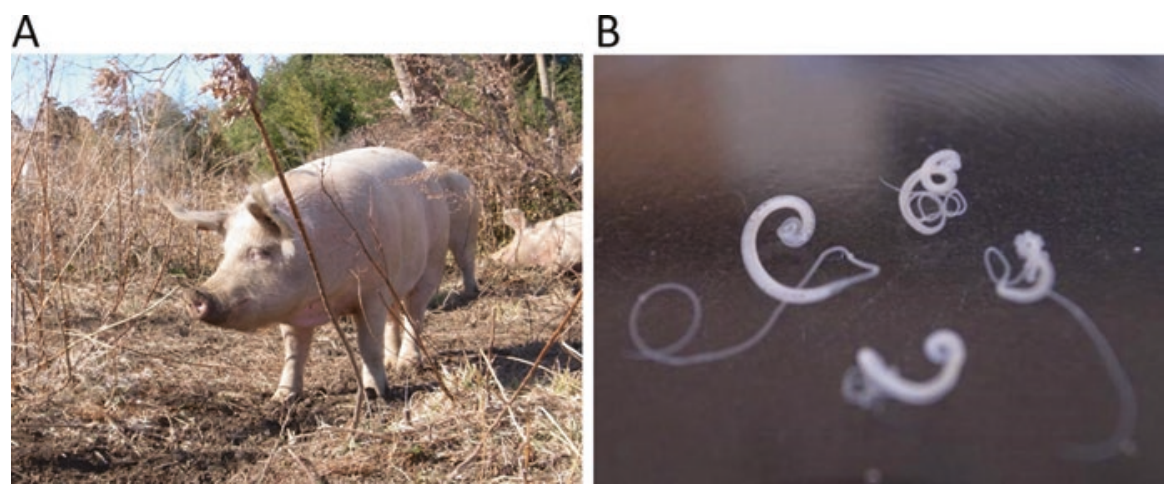

Fig. 11.1 (a) An abandoned unleashed pig in the ex-evacuation zone in 2012. (b) Trichuris suis collected from the pig cecum

\subsubsection{Microarray Analysis}

To identify the genes that were up- or down-regulated by radiation in the exevacuation zone, RNA was extracted for cDNA microarray analysis from the small intestine, which is highly sensitive to radiation [17]. The number of differentially expressed genes with a $\geq 2$-fold change was 5,135. Various immune-related genes were up-regulated in abandoned pigs caught in 2012 [16]. Table 11.1 shows upregulated genes that are involved in NF- $\mathrm{KB}$ activation, oxidative stress and inflammatory immune responses. We found that many genes involved in responses to oxidative stress were up-regulated.

\subsubsection{Real-Time PCR Analysis}

The alterations in gene expression could be considered as the evidence of changes in physiological function after exposure to radiation. We have already reported that some of the selected genes did not show any changes; however, some showed significant differences. As previously reported [16], the expression levels of the AIFM1, IFN- $\gamma$ and TLR3 genes were significantly higher in abandoned pigs than in control pigs. However, the expression levels of cyclin G1, GADD45A, XRCC1, Smad7, XAB2, XPC, OGG1 and EPHX2 were similar in both groups. Here, we reprint the results of expression of the IFN- $\gamma$ gene obtained in our previous study in Fig. 11.2a. The expression ratio and the elevation of IFN- $\gamma$ showed large interindividual differences. Therefore, we next focused on the relationship between gene expression and ${ }^{137} \mathrm{Cs}$ concentration because if radiation causes inflammation through oxidative stress, the elevation of IFN- $\gamma$ expression might be related to the level of radiation exposure of each pig. Figure $11.2 \mathrm{~b}$ is a modified version of a figure from our previous report [16]. IFN- $\gamma$ gene expression was associated with ${ }^{137} \mathrm{Cs}$ concentration in the muscle $\left(y=0.3687 \times 10^{-6} \pm 0.1342 \times 10^{-6} x+0.05727 \pm 0.002299\left[R^{2}=0.3502\right]\right)$. 
Table 11.1 The number of significantly differentially expressed genes ( $>2$-fold) linked to immune responses by microarray data analysis

\begin{tabular}{l|l|l}
\hline Category & $\begin{array}{l}\text { The number of } \geq 2 \text {-fold } \\
\text { change genes in category }\end{array}$ & $p$-Value \\
\hline $\begin{array}{l}\text { Cytokine production involved in inflammatory } \\
\text { response }\end{array}$ & 2 & 0.034 \\
\hline $\begin{array}{l}\text { Negative regulation of NF-kappaB transcription factor } \\
\text { activity }\end{array}$ & 8 & 0.004 \\
\hline $\begin{array}{l}\text { Negative regulation of cytokine production involved in } \\
\text { inflammatory response }\end{array}$ & 2 & 0.034 \\
\hline $\begin{array}{l}\text { Regulation of cytokine production involved in } \\
\text { inflammatory response }\end{array}$ & 2 & 0.034 \\
\hline $\begin{array}{l}\text { Regulation of intrinsic apoptotic signaling pathway in } \\
\text { response to oxidative stress }\end{array}$ & 3 & 0.021 \\
\hline $\begin{array}{l}\text { Positive regulation of intrinsic apoptotic signaling } \\
\text { pathway in response to oxidative stress }\end{array}$ & 3 & 0.011 \\
\hline $\begin{array}{l}\text { Positive regulation of response to oxidative stress } \\
\text { Regulation of response to oxidative stress }\end{array}$ & 3 & 0.011 \\
\hline Response to oxidative stress & 28 & 0.021 \\
\hline Cellular response to oxidative stress & 17 & 0.007 \\
\hline $\begin{array}{l}\text { Positive regulation of cellular response to oxidative } \\
\text { stress }\end{array}$ & 3 & 0.014 \\
\hline Regulation of cellular response to oxidative stress & 3 & 0.011 \\
\hline
\end{tabular}

A

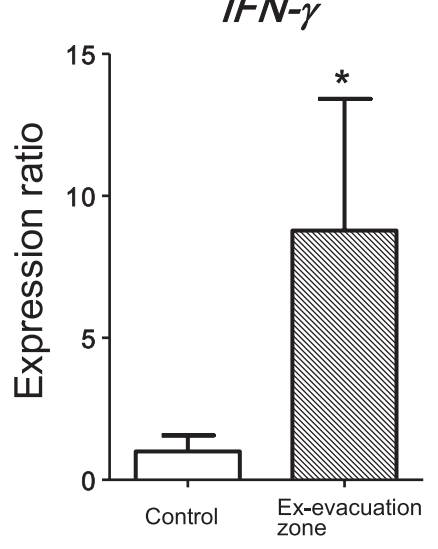

B
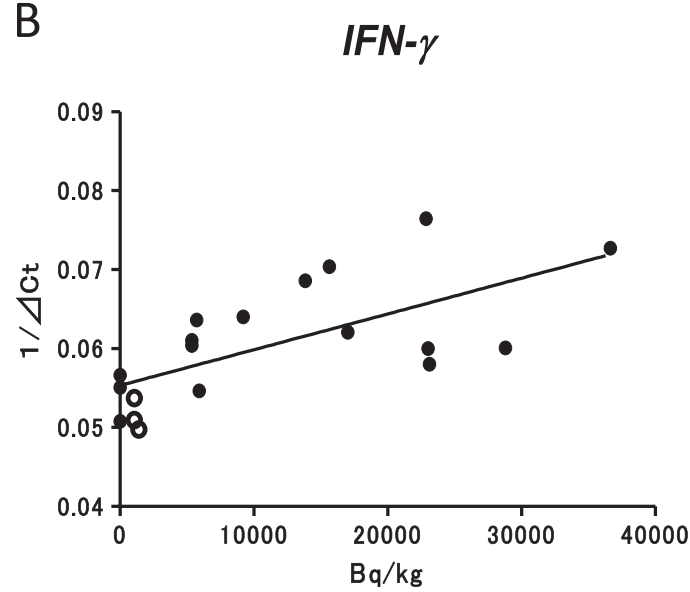

Fig. 11.2 (a) Real-time PCR analysis of IFN- $\gamma$ gene expression in the small intestine of control pigs $(n=3)$ and pigs from the ex-evacuation zone in $2012(n=13)$. All data are expressed in relative units compared with control pigs. $* P<0.05$. Data are presented as mean \pm S.E. B: ${ }^{137} \mathrm{Cs}$ concentration in skeletal muscle and expression of each gene (black circle, pigs in the ex-evacuation zone; white circle, control). A positive correlation was observed between muscle radioactivity and expression of IFN- $\gamma\left(R^{2}=0.3502\right)$. (a) Is reprinted and (b) is modified from our previous report [16] 


\subsubsection{Plasma Biochemistry}

Plasma biochemistry refers to the chemical analysis of blood plasma which reflects the function of crucial organs. Most of the abandoned pigs examined (49/53) showed within the normal levels of GOT and the median value was also in the normal range (Fig.11.3a). Four out of 53 abandoned pigs showed high levels of GOT, which could be attributed to parasitic infection as a possible explanation. Adult Ascaris suum is a common roundworm in pigs worldwide. The migration of the larvae of this species through the liver causes parasite-induced liver inflammation. However, we did not find Ascaris suum in abandoned pigs.

Blood urea nitrogen (BUN) reflects the kidney function. The BUN value of half of the abandoned pigs was outside the normal range (Fig.11.3b). The detailed reason is not clear, but elevated BUN might be due to dehydration resulting from not drinking enough, and lower BUN might be due to the poor nutritional condition, especially low-protein diet.

Total cholesterol (TCHO) is an indicator of nutritional condition. About half of the abandoned pigs examined showed levels of TCHO below the normal range (Fig.11.3c), which could be attributed to a lack of concentrated feed.
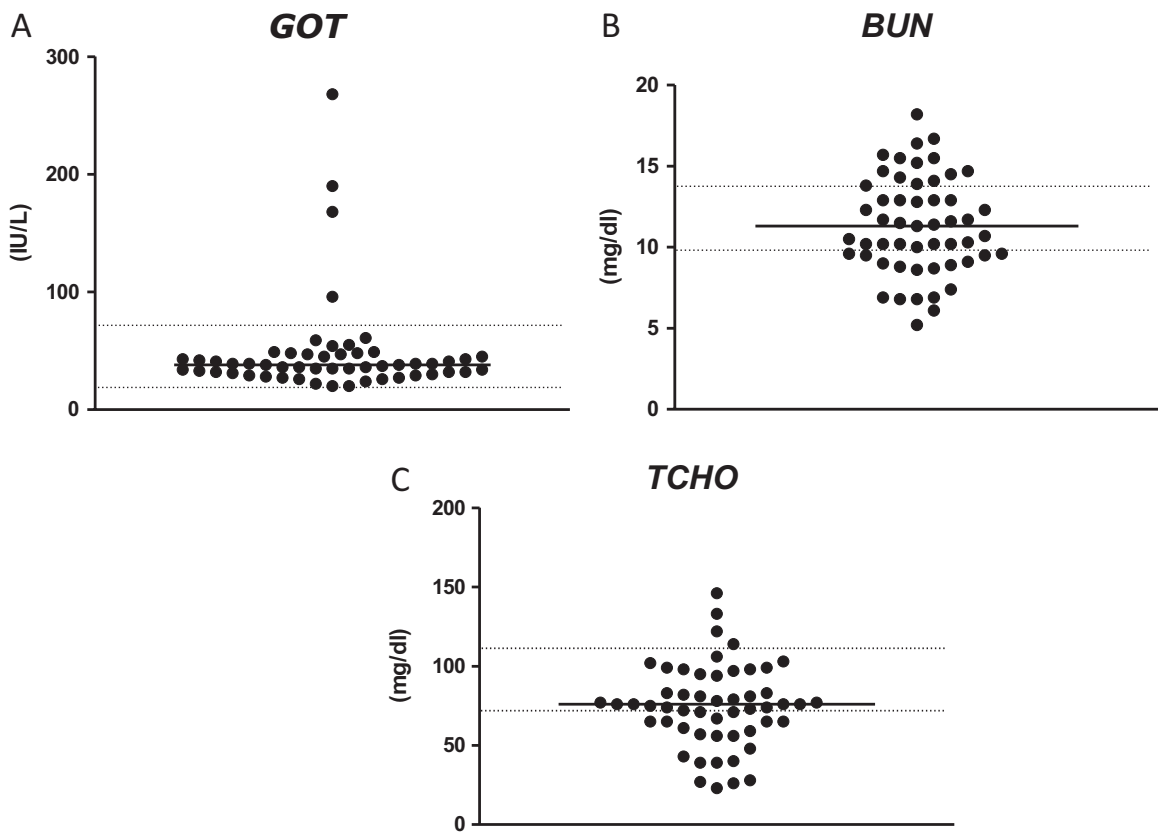

Fig. 11.3 Biochemical analysis of peripheral blood from abandoned pigs. (a) GOT: glutamic oxaloacetic transaminase; (b) BUN: blood urea nitrogen; (c) TCHO: total cholesterol $(n=53)$. Normal ranges are indicated with dashed lines 


\subsubsection{Pathological and Morphological Changes in the Small Intestine}

As we previously reported that there were no remarkable changes including fibrosis in the intestinal tissues of abandoned pigs [16]. Despite the highly elevated IFN- $\gamma$ gene expression, there were no pathological or morphological changes in both the abandoned and the non-affected control groups (Fig.11.4).

\subsection{Discussion}

The Great East Japan Earthquake and tsunami struck the Tohoku (east-north) area of Japan in 2011. The Japanese authorities eventually recategorized the situation at FNPP as a level 7 incident on the International Nuclear Event Scale. A maximum of 164,865 people were evacuated from the ex-evacuation zone, within a 20 -km radius from FNPP.

Before the earthquake, livestock farming was thriving in this area. More than 184,000 pigs and 74,000 beef cattle were raised in the whole of Fukushima Prefecture in February 2011 [18]. However, the livestock were abandoned in the

A Control

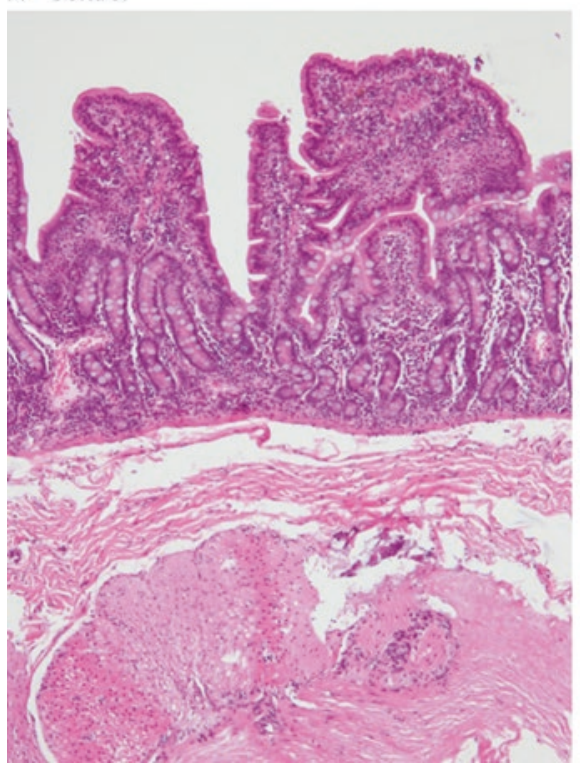

\section{B Fukushima}

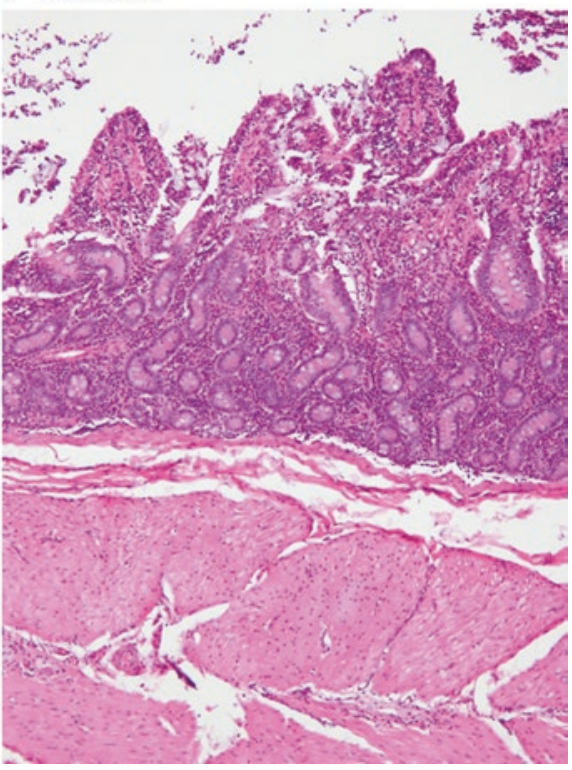

Fig. 11.4 Representative images of hematoxylin and eosin staining. (a) Control; (b) an abandoned pig. All images were acquired from $4-\mu \mathrm{m}$-thick sections at $40 \times$. The results suggest no morphologically remarkable changes in the small intestine of abandoned pigs after the accident 
ex-evacuation zone and most of them have already been euthanized. Our goal here was to accurately analyze the effect of radiation on the animals, to archive all of the data and to present them in a useful format for future generations. This is because such rare data from a contaminated area are very important for understanding biological reactions to radiation in vivo.

As mentioned above, the immune system is extremely important for maintaining homeostasis and tissue repair during radiation stress. However, many conflicting results have been obtained from researches on the interaction between ionizing radiation and the immune system. As Tang et al. stated in their review, various animal models have been investigated in complex conditions to assess the bioeffects of low-dose or low-dose-rate (LD/LDR) radiation [19]. The mechanisms behind LD/ LDR radiation-induced alterations differ depending on the animal species, strain, age, sex and organ. In an investigation on immunological effects, C57BL/6 mice exposed to 0.01-3.0 Gy of X-rays demonstrated a higher level of TNF- $\alpha$ at $24 \mathrm{~h}$ after irradiation, while the elevation of TGF- $\beta$ expression was identified in CBA mice [20]. TGF- $\beta$ expression was also highly increased at 3 days postirradiation in Balb/c mice irradiated with $0.1-5$ Gy of $\gamma$-irradiation [21]. TGF- $\beta$ has antiproliferative and cell cycle regulatory activities and is also well known to play an important role in genomic stability. TGF- $\beta$ is also known as a unique cytokine that acts in inducing regulatory $\mathrm{T}$ cells (Tregs), which inhibit excessive immune responses and in tissue repair to induce fibrosis. $\mathrm{TNF}-\alpha$ is involved in inflammatory responses linked to NF-kB activation. TNF- $\alpha$ and its signaling molecules are key regulators of ROS/oxidative-induced cell death [22]. The alteration of TNF- $\alpha$ and TGF- $\beta$ levels has been observed after exposure to LD radiation in different model systems. Therefore, the monitoring of inflammatory molecules in abandoned animals would be useful to assess the effect of the FNPP accident.

As shown in Fig. 11.1a, the abandoned pigs were living freely and thus could have consumed contaminated insects, soil, water and plants. Therefore, we considered that the effect of radiation might have appeared in the gastrointestinal tract. It is well known that the gastrointestinal tract is highly sensitive to radiation. The intestine has simple columnar epithelium of which cells are tied together with tight junctions, making it a robust barrier to protect the mucosa. The expression of adhesion factors, such as zo-1, zo-2 and afadin, which are scaffold proteins, has also been reported to be altered by radiation [23]. Once disruption of the mucosal barrier has occurred, the gut immune system is activated. The gut mucosa is the largest and the most dynamic immunological environment in the body. Veeraraghave et al. observed NF- $\kappa \mathrm{B}$ activation in the gut after 10-50 cGy of $\gamma$-radiation, which in turn causes the up-regulation of several genes [24]. In this study, we also found the upregulation of genes involved in NF- $\mathrm{KB}$ activation and oxidative stress in the gut of abandoned pigs, through microarray analysis (Table 11.1). Yu et al. demonstrated that LDR radiation promotes dendritic cell migration and IL-12 secretion through the NF- $\kappa$ B pathway [25]. IL-12 is one of the most important cytokines for the initiation of inflammatory responses. As we have already described, quantitative gene expression analysis revealed that IFN- $\gamma$ gene expression was up-regulated in abandoned pigs. In addition, there was a significant correlation between ${ }^{137} \mathrm{Cs}$ 
concentration, that is, dose-rate in skeletal muscle and IFN- $\gamma$ gene expression. However, plasma biochemistry suggested that most of the abandoned pigs examined did not have any problems with their health. According to the data of GOT, some of the abandoned pigs might have been infected with A. suum in the past. The larvae of this species migrate from the cecum to the liver, resulting in parasitic hepatitis [26]. In addition, as shown in Fig. 11.1b, some abandoned pigs were infected with $T$. suis, which does not normally cause severe symptoms in the host. In general, nematode infection usually induces Th2 cytokines in the host [27-29], but we did not detect any elevation of IL-4 and IL-10 in abandoned pigs (data not shown). Therefore, we considered that the increase of IFN- $\gamma$ gene expression in abandoned pigs was not due to parasitic infection. As mentioned above, IFN- $\gamma$ is one of the inflammatory cytokines acting in host defense against viral and bacterial infections. Moreover, IFN- $\gamma$ has pleiotropic effects, including the inhibition of cell proliferation, angiogenesis and apoptosis; in other words, it exerts antitumor effects [30-32]. Zaidi and Merlino stated that the effect of IFN- $\gamma$ is dependent on the cellular, microenvironmental and/or molecular context [33]. As shown in Fig. 11.4, no pathological changes in the intestinal tissue were observed and the animals did not show any abnormal health condition. Therefore, the elevation of IFN- $\gamma$ in abandoned pigs is thought to have been due to host defense against radiation, which could work to maintain the physiological functions in a harsh environment. A previous study demonstrated that the guanine nucleotide-binding protein 1 (GBP1) is one of the genes most strongly induced by interferons. Its overexpression is necessary for the clinically relevant radioresistant phenotype (resistant against persistent exposure to 2 Gy/day of fractionated X-rays) in human cancer cells through inhibiting apoptosis. Thus, IFN- $\gamma$ gene overexpression in this study suggests that adaptive response against $\mathrm{LD} / \mathrm{LDR}$ radiation is induced in small intestine of pigs in the ex-evacuation zone [34]. However, at present, we cannot draw any definitive conclusions on whether the elevation of IFN- $\gamma$ represents a form of protection or damage in the host. More analyses are required to elucidate the effect of long-term LDR radiation exposure in living organisms. We thus need to continue monitoring wild animals in the ex-evacuation zone.

\section{References}

1. Abbas AK, Lichtman AH, Pillai S (2017) Cellular and molecular immunology. Elsevier, Philadelphia

2. Muller B (2002) Cytokine imbalance in non-immunological chronic disease. Cytokine 18(6):334-339

3. Chizzolini C, Dayer JM, Miossec P (2009) Cytokines in chronic rheumatic diseases: is everything lack of homeostatic balance? Arthritis Res Ther 11(5):246

4. United Nations Scientific Committee on the Effects of Atomic Radiation: UNSCEAR 2006 Report Volume II (2006) Effects of ionizing radiation. In: Effects of ionizing radiation on the immune system 
5. Ghosh S, Hayden MS (2008) New regulators of NF-kappaB in inflammation. Nat Rev Immunol 8(11):837-848

6. Multhoff G, Molls M, Radons J (2011) Chronic inflammation in cancer development. Front Immunol 2:98

7. Hayashi T, Kusunoki Y, Hakoda M et al (2003) Radiation dose-dependent increases in inflammatory response markers in A-bomb survivors. Int J Radiat Biol 79(2):129-136

8. Matsuoka Y, Nakayama H, Yoshida R et al (2016) IL-6 controls resistance to radiation by suppressing oxidative stress via the Nrf2-antioxidant pathway in oral squamous cell carcinoma. Br J Cancer 115(10):1234-1244

9. Lugade AA, Sorensen EW, Gerber SA et al (2008) Radiation-induced IFN-gamma production within the tumor microenvironment influences antitumor immunity. J Immunol 180(5):3132-3139

10. Gerber SA, Sedlacek AL, Cron KR et al (2013) IFN-gamma mediates the antitumor effects of radiation therapy in a murine colon tumor. Am J Pathol 182(6):2345-2354

11. Bode G, Clausing P, Gervais F et al (2010) The utility of the minipig as an animal model in regulatory toxicology. J Pharmacol Toxicol Methods 62(3):196-220

12. Dawson HD, Beshah E, Nishi S et al (2005) Localized multigene expression patterns support an evolving Th1/Th2-like paradigm in response to infections with toxoplasma gondii and Ascaris suum. Infect Immun 73(2):1116-1128

13. Swindle MM, Makin A, Herron AJ et al (2012) Swine as models in biomedical research and toxicology testing. Vet Pathol 49(2):344-356

14. Fukuda T, Kino Y, Abe $Y$ et al (2013) Distribution of artificial radionuclides in abandoned cattle in the evacuation zone of the Fukushima Daiichi nuclear power plant. PLoS One 8(1):e54312

15. Yamashiro H, Abe Y, Hayashi G et al (2015) Electron probe X-ray microanalysis of boar and inobuta testes after the Fukushima accident. J Radiat Res 56(Suppl 1):i42-i47

16. Morimoto M, Kato A, Kobayashi J et al (2017) Gene expression analyses of the small intestine of pigs in the ex-evacuation zone of the Fukushima Daiichi Nuclear Power Plant. BMC Vet Res 13(1):337

17. Somosy Z, Horvath G, Telbisz A et al (2002) Morphological aspects of ionizing radiation response of small intestine. Micron 33(2):167-178

18. http://www.maff.go.jp/e/index.html

19. Tang FR, Loke WK, Khoo BC (2017) Low-dose or low-dose-rate ionizing radiation-induced bioeffects in animal models. J Radiat Res 58(2):165-182

20. Irons SL, Serra V, Bowler D et al (2012) The effect of genetic background and dose on nontargeted effects of radiation. Int J Radiat Biol 88(10):735-742

21. Ehrhart EJ, Segarini P, Tsang ML et al (1997) Latent transforming growth factor beta1 activation in situ: quantitative and functional evidence after low-dose gamma-irradiation. FASEB J 11(12):991-1002

22. Shen HM, Lin Y, Choksi S et al (2004) Essential roles of receptor-interacting protein and TRAF2 in oxidative stress-induced cell death. Mol Cell Biol 24(13):5914-5922

23. Somosy Z, Bognar G, Horvath G et al (2003) Role of nitric oxide, cAMP and cGMP in the radiation induced changes of tight junctions in Madin-Darby canine kidney cells. Cell Mol Biol (Noisy-le-Grand) 49(1):59-63

24. Veeraraghavan J, Natarajan M, Herman TS et al (2011) Low-dose gamma-radiation-induced oxidative stress response in mouse brain and gut: regulation by NFkappaB-MnSOD crosssignaling. Mutat Res 718(1-2):44-55

25. Yu N, Wang S, Song X et al (2018) Low-dose radiation promotes dendritic cell migration and IL-12 production via the ATM/NF-kappaB pathway. Radiat Res 189:409

26. Douvres FW, Tromba FG, Malakatis GM (1969) Morphogenesis and migration of Ascaris suum larvae developing to fourth stage in swine. J Parasitol 55(4):689-712

27. Gause WC, Ekkens M, Nguyen D et al (1999) The development of CD4+ T effector cells during the type 2 immune response. Immunol Res 20(1):55-65 
28. Morimoto M, Saito C, Muto C et al (2015) Impairment of host resistance to helminthes with age in murine small intestine. Parasite Immunol 37(4):171-179

29. Urban JF Jr, Madden KB, Svetic A et al (1992) The importance of Th2 cytokines in protective immunity to nematodes. Immunol Rev 127:205-220

30. Beatty G, Paterson Y (2001) IFN-gamma-dependent inhibition of tumor angiogenesis by tumor-infiltrating CD4+ T cells requires tumor responsiveness to IFN-gamma. J Immunol 166(4):2276-2282

31. Chawla-Sarkar M, Lindner DJ, Liu YF et al (2003) Apoptosis and interferons: role of interferon-stimulated genes as mediators of apoptosis. Apoptosis 8(3):237-249

32. Coughlin CM, Salhany KE, Gee MS et al (1998) Tumor cell responses to IFNgamma affect tumorigenicity and response to IL-12 therapy and antiangiogenesis. Immunity 9(1):25-34

33. Zaidi MR, Merlino G (2011) The two faces of interferon-gamma in cancer. Clin Cancer Res 17(19):6118-6124

34. Fukumoto M, Amanuma T, Kuwahara $Y$ et al (2014) Guanine nucleotide-binding protein 1 is one of the key molecules contributing to cancer cell radioresistance. Cancer Sci 105(10):1351-1359

Open Access This chapter is licensed under the terms of the Creative Commons Attribution 4.0 International License (http://creativecommons.org/licenses/by/4.0/), which permits use, sharing, adaptation, distribution and reproduction in any medium or format, as long as you give appropriate credit to the original author(s) and the source, provide a link to the Creative Commons license and indicate if changes were made.

The images or other third party material in this chapter are included in the chapter's Creative Commons license, unless indicated otherwise in a credit line to the material. If material is not included in the chapter's Creative Commons license and your intended use is not permitted by statutory regulation or exceeds the permitted use, you will need to obtain permission directly from the copyright holder.

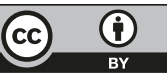

